\title{
PENGEMBANGAN MEDIA PEMBELAJARAN MATEMATIKA DENGAN MENGGUNAKAN SOFTWARE LECTORA INSPIRE PADA MATERI PERBANDINGAN UNTUK SISWA KELAS VII SMP NEGERI 3 SELONG
}

\author{
Rivadatul Mahmudah, Shahibul Ahyan, Ahmad Rasidi \\ Universitas Hamzanwadi \\ riva.datu112@gmail.com
}

\begin{abstract}
Abstrak
Penelitian ini bertujuan untuk mengembangkan software Lectora Inspire pada materi perbandingan. Produk yang dihasilkan dalam penelitian ini adalah media pembelajaran matematika menggunakan software Lectora Inspire pada materi perbandingan. Dihasilkannya produk penelitian ini diharapkan dapat meningkatkan kualitas pembelajaran pada materi perbandingan menggunakan media pembelajaran Lectora Inspire dan menarik minat siswa untuk memahami materi perbandingan dengan konsep menggabungkan teknologi sebagai media penunjangnya dan mengaplikasikan media teknologi dalam proses pembelajaran pada pokok bahasan perbandingan dan media pembelajaran yang dihasilkan dapat menjadi perangkat bantu dan alternatif media pembelajaran matematika. Jenis penelitian ini adalah penelitian dan pengembangan. Produk pembelajaran yang dikembangkan meliputi: aspek visual dan audio, kebahasaan, efek penggunaan media terhadap strategi pembelajaran, dan aspek materi. Ujicoba produk melibatkan ahli media, ahli materi, dan siswa. Hasil ujicoba media pembelajaran yang dikembangkan secara keseluruhan memenuhi kriteria sangat baik dengan persentase sebesar $97 \%$ menurut ahli media dan $86 \%$ menurut ahli materi. Sedangkan menurut respon siswa media tersebut memenuhi kriteria baik dengan persentase sebesar $76 \%$. Sehingga dapat disimpulkan bahwa, media pembelajaran yang dikembangkan berhasil memberikan dampak positif terhadap pengguna, berdasarkan hasil belajar siswa yang tuntas dengan persentase sebesar $74 \%$ dan layak dijadikan sebagai media penunjang proses pembelajaran siswa.
\end{abstract}

Kata kunci: Lectora Inspire, Media Pembelajaran Matematika, Perbandingan

\begin{abstract}
This research aim to develop the software lectora inspire in compression material. This research going to produce media that can be helping the students to improve their quality in mathematic subject especially in compression material. Furthermore, this research aim to use the technology in teaching learning process as the media that can be used as the alternative media in mathematic subject. This research was conducted as the research development, such as: visual aspect and audio, languages, the effect of use teaching strategies and material aspect. This research was involved the media expert, material expert and students response to conduct the research. Totally the media was developed showing the excellent criteria, it is $97 \%$ score based on the media expert and $86 \%$ based on the material expert. Based on the student responses, it shows $76 \%$ as the good criteria. So that why, the researcher can be concluded that this media gave a positive effect for the user, based on the results of students with $74 \%$ score and it can be as the alternative media to conduct teaching learning process.
\end{abstract}

Keywords: Lectora Inspire, Mathematic Teaching Media, and Compression 


\section{PENDAHULUAN}

Matematika merupakan salah satu komponen atau serangkaian mata pelajaran yang mempunyai peranan yang sangat penting dalam dunia pendidikan. Matematika perlu untuk dipelajari disemua elemen masyarakat karena matematika merupakan (1) sarana untuk memecahkan masalah dalam kehidupan sehari-hari, (2) sarana untuk berpikir logis, jelas, dan kritis, (3) sebagai ilmu dasar untuk mempelajari bidang pendidikan lainnya. Johnson dan Rising dalam Offirstson (2014: 2) mengatakan bahwa,

Matematika itu adalah pola berpikir, pola mengorganisasikan, dan pembuktian yang logis, matematika itu bahasa yang menggunakan istilah yang didefinisikan dengan cermat, jelas, dan akurat, refrentasinya dengan simbol dan padat, lebih dari bahasa simbol mengenai ide daripada mengenai bunyi.

Terdapat beberapa kendala yang terjadi dalam proses pembelajaran matematika berkisar pada masalah kurangnya pembelajaran yang digunakan oleh Guru dan kurangya pemanfaatan penggunaan media (komputer) pada saat proses pembelajaran. Masalah yang dihadapi siswa dalam proses pembelajaran pada materi perbandingan yaitu kurangnya media penunjang proses pembelajaran, kurangnya siswa memahami cara membedakan konsep perbandingan senilai dan perbandingan berbalik nilai. Kendala tersebut dapat mengakibatkan kegagalan pada siswa, hal ini bisa terjadi karena (1) siswa tidak dapat memahami konsep dengan benar, (2) pembelajaran tidak berjalan efektif dan efisien disebabkan karena tidak ada timbal balik yang terjadi pada proses pembelajaran, (3) Nilai siswa dibawah nilai rata-rata Kriteria Ketuntasan Minimal (KKM) yang sudah ditetapkan oleh pihak sekolah sebesar 70 .

Pembelajaran matematika yang menarik dan menyenangkan mampu menarik minat siswa untuk berperan aktif dalam proses pembelajaran serta mampu melahirkan siswa yang berprestasi salah satu cara pembelajaran matematika yang dianggap menyenangkan siswa yaitu penggunaan media sebagai sarana pembelajaran. Jika dicermati, banyak Guru yang menganggap bahwa media hanya sebatas alat bantu yang diabaikan ketika media tersebut tidak ada. Padahal jika dicermati, media akan memberikan kontribusi yang sangat besar bagi tercapainya tujuan pembelajaran yang diharapkan.

Mengantisipasi masalah tersebut agar tidak berkelanjutan dalam proses pembelajaran maka perlu adanya pemanfaatan media pembelajaran salah satunya dengan menggunakan Lectora Inspire. Pengembangan media pembelajaran menggunakan Lectora Inspire pernah juga dilakukan oleh Yuswanto (2015) yang bertujuan untuk mengembangkan prosedur pengembangan dan untuk 
mengetahui kualitas media pembelajaran IPA berbasis Lectora Inspire untuk kelas V MI/SD semester II dari beberapa ahli, peer reviewer, guru wali kelas, dan respon siswa. Berdasarkan hasil penilaian oleh para ahli, peer reviewer, dan guru wali kelas V media pemmbelajaran IPA termasuk dalan kategori Sangat Baik. Respon siswa terhadap media pembelajaran IPA dalam ujicoba lapangan secara keseluruhan memperoleh kategori penilaian "Positif". Persentase respon siswa yang merespon positif produk sebesar 100\%. Berdasarkan hasil penelitian ini menunjukkan bahwa Media Pembelajaran IPA Berbasis Lectora Inspire untuk Kelas V MI/SD Semester II yang dikembangkan dapat dijadikan sebagai salah satu media pembelajaran IPA. Lectora Inspire adalah perangkat lunak authoring tools atau alat pengembangan pembelajaran elektronik yang menggabungkan unsur teks, gambar, suara, dan video menjadi sebuah media pembelajaran yang interaktif yang dikembangkan oleh Trivantis Corp. Oleh karena itu peneliti tertarik melakukan penelitian tentang "Pengembangan Media Pembelajaran Matematika Dengan Menggunakan Software Lectora Inspire Pada Materi Perbandingan Untuk Siswa Kelas VII SMPN 3 Selong”.

\section{METODE}

Metode penelitian yang digunakan pada penelitian ini adalah metode penelitian Research and Development (R\&D). Sebagaimana yang digunakan oleh Sugiyono bahwa penelitian Research and Development adalah penelitian yang digunakan untuk menghasilkan produk tertentu, dan untuk menguji keefektifan produk tersebut, berikut langkah-langkahnya: (1) Potensi dan Masalah (2) Mengumpulkan Informasi (3) Desain Produk (4) Validasi Desain (5) Revisi Desain (6) Ujicoba Produk (7) Revisi Produk (8) Ujicoba Pemakaian (9) Revisi Produk. Instrumen yang digunakan dalam penelitian ini antara lain: instrumen validasi ahli media dan ahli materi, instrumen penilaian media pembelajaran oleh siswa, dan data hasil belajar siswa.

Validasi media pembelajaran dilakukan dengan cara menghadirkan beberapa pakar atau tenaga ahli yang sudah berpengalaman dibidangnya untuk menilai media pembelajaran yang telah dibuat peneliti. Peneliti meminta penilaian dari dua orang ahli media dan dua orang ahli materi. Setelah melalui proses validasi, media pembelajaran direvisi berdasarkan saran ahli. Selanjutnya media pembelajaran diujicobakan kepada subjek ujicoba. Subjek ujicoba pada penelitian ini adalah kelas VII E sebanyak 23 siswa SMP Negeri 3 Selong.

Teknik analisis data yang diperoleh dari angket dapat dianalisis dengan teknik persentase. 


\section{Analisis Kelayakan}

Data yang digunakan untuk menilai kelayakan media pembelajaran adalah data angket dari validator. Teknik yang digunakan adalah teknik rata-rata untuk setiap kriteria kemudian menggunakan teknik analisis persentase untuk analisis penilaian akhir media dengan rumus sebagai berikut:

Persentase Untuk Kelayakan Masing-Masing Kriteria

$$
P=\frac{\text { jumlah skor hasil pengumpulan data }}{\text { jumlah skor kriteria }} \times 100 \%
$$

Keterangan:

$P=$ persentase kelayakan media

Tabel 1. Kriteria Kualitatif

\begin{tabular}{|c|c|}
\hline Skor Persentase (\%) & Interpretasi \\
\hline $0-20$ & Sangat Kurang \\
\hline $21-40$ & Kurang \\
\hline $41-60$ & Cukup Baik \\
\hline $61-80$ & Baik \\
\hline $81-100$ & Sangat Baik \\
\hline
\end{tabular}

\section{Analisis Instrumen Penilaian Media Pembelajaran Oleh Siswa}

Data yang diperoleh dari angket yang sudah diisi oleh siswa selanjutnya dianalisis untuk mengetahui respon siswa terhadap media pembelajaran yang dibuat peneliti.

Tabel 2. Pedoman skor penilaian siswa

\begin{tabular}{|c|c|c|c|c|c|}
\hline \multirow{2}{*}{$\begin{array}{c}\text { Pernytaan } \\
\text { Respon }\end{array}$} & \multicolumn{5}{|c|}{ Kriteria } \\
\cline { 2 - 6 } & $\begin{array}{l}\text { Sangat } \\
\text { Setuju }\end{array}$ & Setuju & $\begin{array}{c}\text { Cukup } \\
\text { Setuju }\end{array}$ & $\begin{array}{c}\text { Tidak } \\
\text { Setuju }\end{array}$ & $\begin{array}{c}\text { Sangat } \\
\text { Tidak } \\
\text { Setuju }\end{array}$ \\
\hline Positif & 5 & 4 & 3 & 2 & 1 \\
\hline Negatif & 1 & 2 & 3 & 4 & 5 \\
\hline
\end{tabular}

$$
P=\frac{\text { jumlah skor hasil pengumpulan data }}{\text { jumlah skor kriteria }} \times 100 \%
$$

Keterangan:

$P=$ persentase kelayakan media 


\section{Analisis Instrumen Data Hasil Belajar Siswa}

Data dari hasil belajar siswa ini dianalisis untuk menentukan keberhasilan dari produk media pembelajaran berdasarkan ketuntasan hasil belajar siswa secara klasikal.

Persentase ketuntasan belajar siswa secara klasikal sebanyak 70\% menggunakan rumus sebagai berikut:

$$
P=\frac{f}{n} X 100 \%
$$

Keterangan:

$P=$ persentase ketuntasan hasil belajar siswa secara klasikal

$f=$ frekuensi jawaban

$n=$ banyak responden

\section{HASIL PENGEMBANGAN DAN PEMBAHASAN}

Penelitian dan pengembangan ini menghasilkan media pembelajaran matematika menggunakan software Lectora Inspire pada materi perbandingan. Model media pembelajaran ini adalah model aplikasi yang diawali dengan penyajian materi yang dilengkapi dengan flypaper, latihan soal yang disajikan pada materi perbandingan dilengkapi dengan flash dan diakhiri dengan kuis (evaluasi) yang dilengkapi dengan waktu dalam menjawab soal dan soal pilihan jawaban kuis (evaluasi) dibuat secara random untuk meminimalisir siswa untuk mencontek maupun bekerja sama serta dilengkapi dengan hasil kuis (evaluasi) yang telah dijawab oleh siswa secara transparan. Seperti yang telah disebutkan bahwa sasaran penggunaan media pembelajaran ini adalah siswa kelas VII E SMP Negeri 3 Selong. Media pembelajaran ini dikembangkan menggunakan software Lectora Inspire. Media pembelajaran ini ditampilkan pada komputer dan dilengkapi dengan software pendukung seperti Flash Player 10.exe dan QuickTime Player yang berfungsi agar tampilan media pembelajaran matematika menggunakan software Lectora Inspire sempurna. Untuk menjalankan media pembelajaran software Lectora Inspire hanya dilakukan double click pada desktop yang diberi nama perbandingan.exe. Berikut beberapa tampilan dari media pembelajaran software Lectora Inspire. 


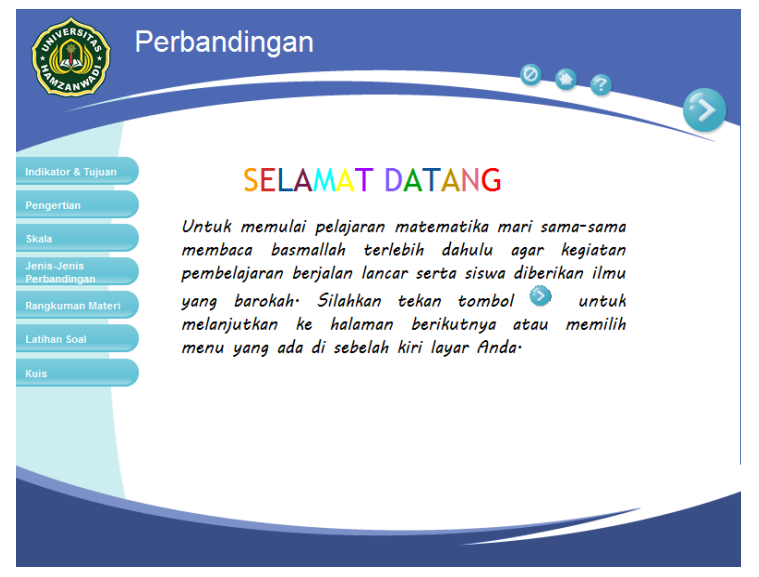

Gambar 1 Tampilan Halaman Utama

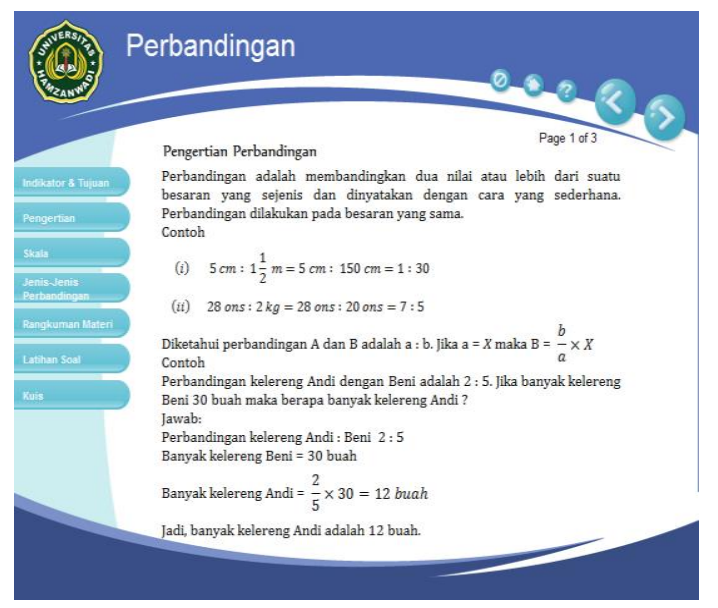

Gambar 3 Tampilan Materi

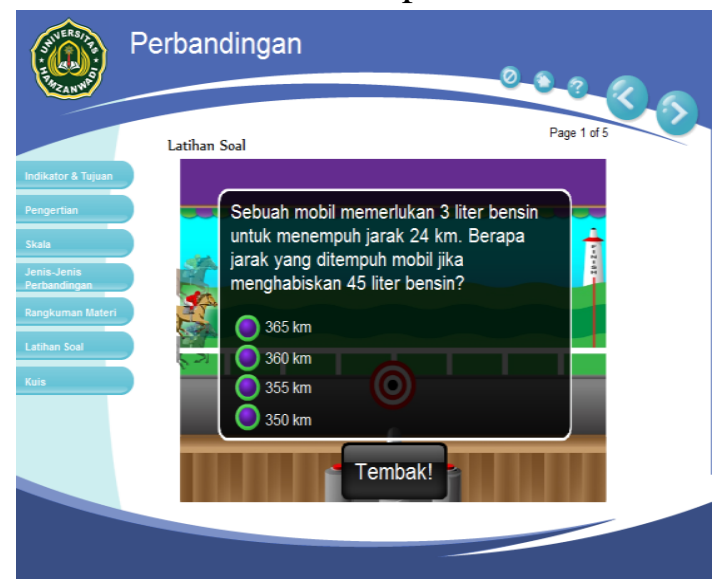

Gambar 5 Tampilan Latihan Soal

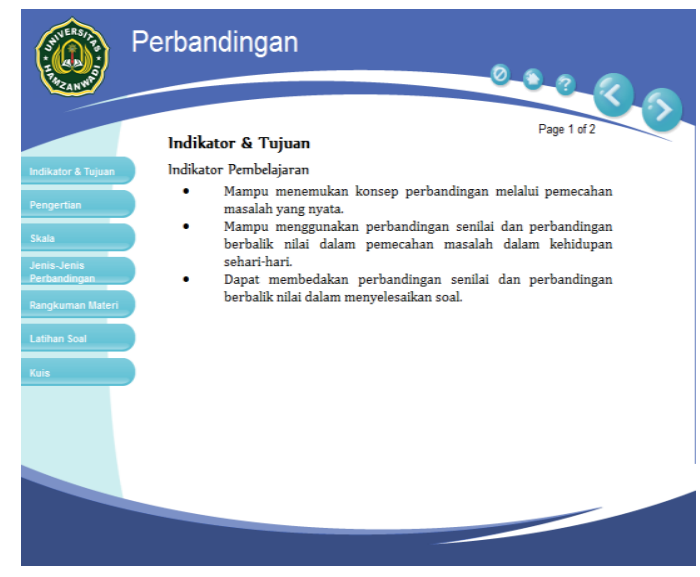

Gambar 2 Tampilan Menu Utama

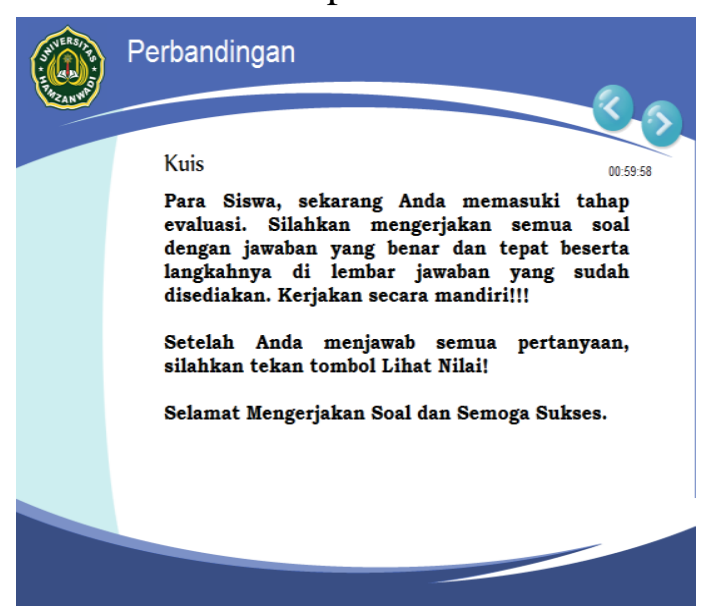

Gambar 4 Tampilan Awal Kuis

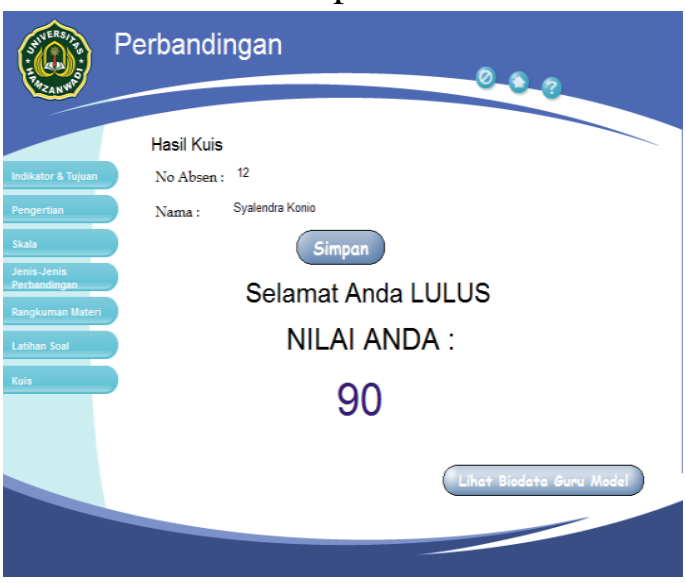

Gambar 6 Tampilan Hasil Kuis

Media yang dikembangkan tersebut telah melalui tahap validasi dan ujicoba produk. Dari kegiatan validasi dan ujicoba produk diperoleh beberapa data selanjutnya dianalisis untuk mengetahui apakah media pembelajaran tersebut berkualitas baik yaitu memenuhi kriteria layak dan efektif. Data yang berupa data numerik dianalisis menggunakan rumus yang telah ditetapkan 
serta data verbal berupa saran dari ahli media, materi dan siswa digunakan untuk memperbaiki media pembelajaran. Berikut disajikan hasil dari analisis data yang telah diperoleh:

\section{Deskripsi Hasil Validasi Oleh Ahli Materi dan Ahli Media}

Aspek yang dinilai oleh ahli materi dan ahli media dalam media pembelajaran ini adalah aspek visual dan audio, kebahasaan, efek penggunaan media terhadap strategi pembelajaran, dan materi.

Tabel 3. Hasil Validasi Oleh Ahli Materi dan Ahli Media

\begin{tabular}{|c|l|c|c|c|}
\hline No. & \multicolumn{1}{|c|}{ Aspek } & $\begin{array}{c}\text { Persentase } \\
\text { perolehan } \\
\text { skor }(\%) \text { oleh } \\
\text { ahli materi }\end{array}$ & $\begin{array}{c}\text { Persentase } \\
\text { perolehan skor } \\
(\%) \text { oleh ahli } \\
\text { media }\end{array}$ & Kriteria \\
\hline 1 & Visual dan Audio & 90 & 98 & Sangat Baik \\
\hline 2 & Kebahasaan & 90 & 100 & Sangat Baik \\
\hline 3 & $\begin{array}{l}\text { Efek penggunaan media } \\
\text { terhadap strategi } \\
\text { pembelajaran }\end{array}$ & 84 & 94 & Sangat Baik \\
\hline 4 & Materi & 83 & - & Sangat Baik \\
\hline & \multicolumn{1}{|c|}{ Rata-rata } & 86 & 97 & Sangat Baik \\
\hline
\end{tabular}

Persentase hasil rata-rata analisis pada tabel 3 , berdasarkan validasi ahli materi dan ahli media, media pembelajaran yang dikembangkan peneliti termasuk dalam kriteria sangat baik untuk digunakan dalam pembelajaran matematika.

\section{Deskripsi dan Analisis Ujicoba Pemakaian Oleh Siswa}

Ujicoba pemakaian produk dilakukan pada siswa kelas VII E yang berjumlah 23 siswa. Tahap ini dilakukan untuk mengetahui efektivitas produk yang dikembangkan dan memperoleh masukan untuk melakukan revisi tahap akhir.

a. Analisis Respon Siswa

Tahap ini dilakukan untuk mengetahui efektivitas produk yang dikembangkan dan memperoleh masukkan untuk melakukan revisi produk tahap akhir.

Tabel 4. Hasil angket respon siswa

\begin{tabular}{|c|l|c|c|}
\hline No. & \multicolumn{1}{|c|}{ Aspek } & $\begin{array}{c}\text { Persentase } \\
\text { perolehan skor }(\%)\end{array}$ & Kriteria \\
\hline 1 & Visual dan Audio & 77 & Baik \\
\hline 2 & Kebahasaan & 80 & Baik \\
\hline 3 & $\begin{array}{l}\text { Efek penggunaan media terhadap } \\
\text { strategi pembelajaran }\end{array}$ & 72 & Baik \\
\hline 4 & Materi & 71 & Baik \\
\hline \multicolumn{1}{|c|}{ Rata-rata } & 76 & Baik \\
\hline
\end{tabular}


Persentase rata-rata hasil analisis dari setiap aspek sebesar $76 \%$. Sehingga dapat disimpulkan bahwa media pembelajaran yang dikembangkan peneliti menurut respon siswa termasuk dalam kriteria baik untuk digunakan dalam pembelajaran matematika.

b. Analisis Keberhasilan Media Pembelajaran

Analisis keberhasilan dilakukan terhadap data hasil ulangan harian siswa. Persentase ketuntasan hasil belajar siswa ujicoba secara klasikal dengan KKM $\geq 70$ sebesar 74\%. Persentase ketuntasan belajar siswa secara klasikal telah memenuhi kriteria minimal yang ingin dicapai dalam penelitian ini, yaitu $\geq 70 \%$ dari jumlah siswa yang menjadi subjek penelitian ini. Hasil perhitungan data ulangan siswa dapat dilihat pada tabel di bawah.

Tabel 5. Hasil ulangan harian siswa ujicoba

\begin{tabular}{|c|l|c|}
\hline No. & \multicolumn{1}{|c|}{ Variasi } & Jumlah \\
\hline 1 & Nilai tertinggi & 90 \\
\hline 2 & Nilai terendah & 50 \\
\hline 3 & Nilai rata-rata & 72 \\
\hline 4 & Jumlah siswa yang mencapai KKM & 17 \\
\hline 5 & Jumlah keseluruhan siswa & 23 \\
\hline 6 & Ketuntasan klasikal (\%) & 74 \\
\hline
\end{tabular}

Tabel di atas, dapat disimpulkan bahwa media pembelajaran matematika pada materi perbandingan berdasarkan analisis keberhasilan mencapai persentase $74 \%$, yang berarti media pembelajaran ini dinyatakan dapat digunakan sebagai media pembelajaran matematika dalam menunjang proses pembelajaran dan hasil belajar siswa.

\section{SIMPULAN DAN SARAN}

Peneliti dapat mengambil beberapa kesimpulan berdasarkan penelitian yang dilakukan sebagai berikut:

Kualitas media pembelajaran menggunakan software Lectora Inspire pada materi perbandingan untuk siswa kelas VII yang dikembangkan telah dilakukan analisis terhadap penilaian media pembelajaran oleh para ahli dan siswa, maka dapat diketahui tingkat kelayakan media pembelajaran berdasarkan semua responden. Berdasarkan penilaian ahli materi dan ahli media, media pembelajaran menggunakan software Lectora Inspire ini termasuk dalam kriteria sangat baik, dengan tingkat kelayakan sebesar $86 \%$ menurut ahli materi dan 97\% menurut ahli media. Berdasarkan penilaian para siswa kelas VII E, media pembelajaran menggunakan software 
Lectora Inspire ini termasuk dalam kriteria baik, dengan tingkat kelayakan sebesar 76\%. Sehingga dari hasil penilaian beberapa tenaga ahli dan para siswa dapat disimpulkan bahwa hasil akhir pengembangan media ini dinyatakan layak digunakan sebagai media pembelajaran matematika pada materi perbandingan dengan persentase jumlah siswa sebagai subjek ujicoba yang tuntas sebesar $74 \%$.

Peneliti masih menemukan adanya kendala baik dalam keterbatasan mempelajarinya. Peneliti menyarankan beberapa hal yang dapat dikembangkan lebih lanjut, sebagai berikut:

Disarankan kepada pengguna atau peneliti selanjutnya agar menggunakan Operating System Windows 7, Windows 8, ataupun Windows 10 agar software Lectora Inspire berjalan dengan lancar, selanjutnya agar dapat menerapkan media pembelajaran menggunakan software Lectora Inspire pada materi trigonometri karena dalam materi trigonometri terdapat banyak simbol maupun rumus matematika. Media pembelajaran yang dikembangkan menggunakan software Lectora Inspire tidak hanya difokuskan pada komputer, sehingga peneliti selanjutnya perlu mengembangkan lebih lanjut agar dapat diakses pada smartphone dan secara tampilan menggunakan template yang didesain sendiri sehingga desain pada media pembelajaran lebih menarik dan sesuai dengan materi yang ditampilkan serta memperbanyak konten dalam media pembelajaran.

\section{DAFTAR PUSTAKA}

Faiza, Z., \& Rina, H. (2016). Pengembangan Media Pembelajaran Basis Data Berbasis Android Untuk Kelas XI di SMK Negeri 2 Surabaya. Journal IT-Edu. Volume 1, Nomor 1, hal. 9-13.

G, Nirosha. (2016). Effective Online Training Programs Using Lectora Inspire [Infographic]. Diunduh di http://www.elearninglearning.com/lectora/?open-article-id=5575483\&articletitle=effective-online-training-programs-using-lectora-inspire-infographic-\&blogdomain=commlabindia.com\&blog-title=commlab-india tanggal 28 Juni 2017 pukul 12.21 WITA.

Offirstson, T. (2014). Aktivitas Pembelajaran Matematika Melalui Inkuiri Berbantuan Software Cinderella. Yogyakarta: Deepublish.

Rachmawati. (2013). Meningkatkan Hasil Belajar Menggambar Proporsi Tubuh Menggunakan Metode Pembelajaran Driil Kelas X Busana II SMKN 3 Blitar. eJournal. Volume 2, Nomor 1, hal. 60-64.

Sugiyono. (2015). Metode Penelitian Pendidikan (Pendekatan Kuantitatif, Kualititaif, dan R\&D). Bandung: Alfabeta. 
Yuswanto, A. (2015). Pengembangan Media Pembelajaran IPA Berbasis Lectora Inspire untuk Kelas V MI/SD Semester II. Skripsi. Yogyakarta: Program Pascasarjana UIN Sunan Kalijaga Yogyakarta. 